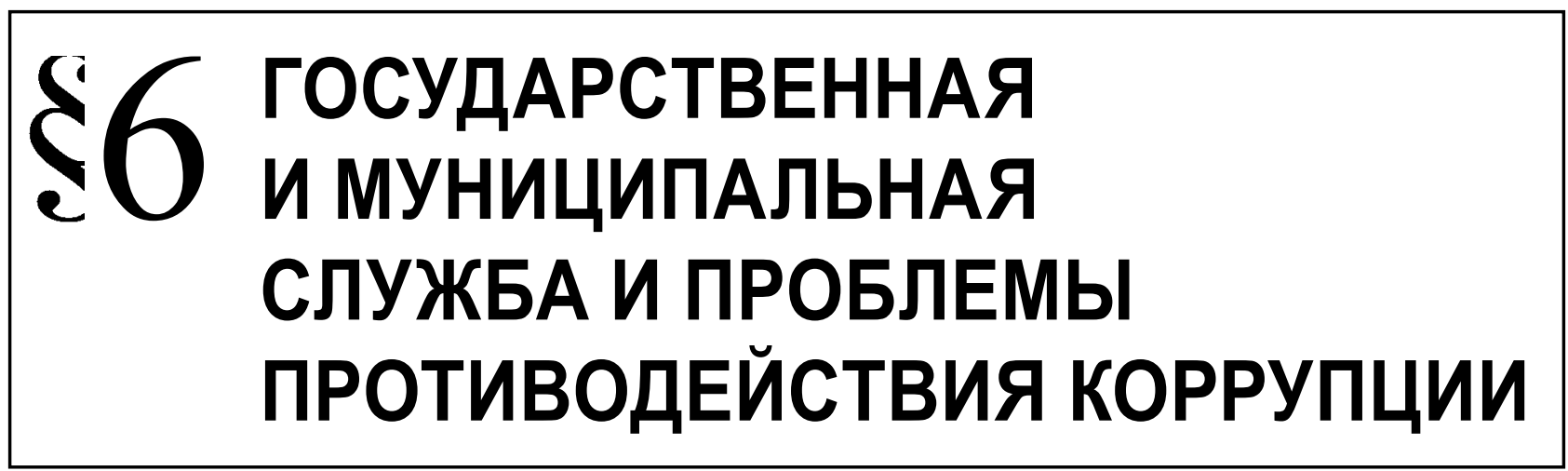

Некрасова Т.А.

\title{
ПРОБЛЕМЫ И ПЕРСПЕКТИВЫ ГОСУДАРСТВЕННО-ЧАСТНОГО ПАРТНЕРСТВА В СФЕРЕ ПРОТИВОДЕЙСТВИЯ КОРРУПЦИИ
}

Аннотация: В статье рассматривается возможность использования механизмов государственно-частного партнерства в связи с противодействием коррупции. В статье отмечается, что подходы к реагированию на частноправовую коррупцию в странах англосаксонской правовой системы являются прогрессивными. Наблюдается позитивная практика привлечения к ответственности за факты подкупа в частной срере не только внутри государства, но и за ее пределами. В то же время, меры предупреждения частноправовой коррупции, а не меры репрессии, считаются наиболее перспективными в рамках компаний. В связи с принятием обязательств по ряду международных антикоррупционных актов (прежде всего Конвенция ООН против коррупции от 31 октября 2003 г и Конвенция ОЭСР о борьбе с подкупом иностранных должностных лиц при осуществлении международных коммерческих сделок ) законодательство Российской Федерации в области предупреждения коррупции подверглось существенным изменениям и дополнениям. Одним из таких дополнений явилось законодательное закрепление мер, направленных на недопущение возникновения коррупции в частноправовой сфере. Так в частности, Ф3 «О противодействии коррупции» был дополнен статьей 13.3 «Обязанность организаций принимать меры по предупреждению коррупции», которой организации были обязаны разрабатывать и принимать меры по предупреждению коррупции. Данные меры при условии их комплексного применения в организации должны иметь своей целью образование и внедрение антикоррупционной политики внутри организации с четкой регламентацией такой деятельности.

Ключевые слова: коррупция, партнерство, борьба, противодействие, воздействие, чиновник, служащий, профилактика, предупреждение, наказание.

$\mathbf{K}$ риминологически значимый характер и природа коррупционных отношений ярко проявляется в частноправовой сфере ведения бизнеса, где деятельность субъектов преимущественно строится на диспозитивных (свободных) началах. По этой причине важно выработать целый комплекс предупредительных мероприятий, которые способствовали бы нивелированию возникновения коррупции в бизнес - среде.

В связи с этим, в вопросе противодействия коррупции в частноправовом секторе крайне важно расставить правильные акценты в дуумвирате «государство - бизнес»

Взаимоотношения между государством и бизнес сообществом установились на современном этапе с конца 80-х годов прошлого века, с момента изменения экономической формации жизнедеятельности современного государства и общества.

Передел собственности сопровождался множеством предикатных по отношению к коррупции криминальных и околокриминальных явлений (рейдерство, рэкет, мошенничество, злоупотребление полномочиями). Совокупность этих явлений, в силу политического характера коррупционного механизма, оказывала влияние на формирование традиций ведения бизнеса в России, которые актуальны по настоящее время.

Делая вывод из недалекого исторического прошлого современной России, нужно согласиться с тем, что государство должно выступает инициа- 
тором и методологом, задающим движение пути во взаимоотношениях частного и публичного ${ }^{1}$. Особенно актуально это звучит в вопросах синергии усилий по противодействию коррупции.

При этом важно, чтобы такая синергия едина по отношению к малому, среднему и крупному бизнесу».

Для начала нужно рассмотреть вопрос взаимоотношений государства и крупного бизнеса в сфере предупреждения коррупции, потому как именно результаты такой совместной деятельности способны оказывать влияние на экономику в целом. Главным здесь выступает определение содержания и направлений государственно-частное партнерства (далее - ГЧП) по вопросам противодействия коррупции.

Понятие ГЧП в рассматриваемом аспекте не сложилось. Нет единых подходов к определению и в научной литературе. В проекте Федерального закона «Об основах государственно-частного партнерства в субъектах Российской Федерации и муниципальных образованиях и о внесении изменений в отдельные законодательные акты Российской Федерации», представленном Министерством экономического развития России в 2012 году², и рядом авторов под ГЧП понимается вид инвестиционной деятельности ${ }^{3}$. Следует признать узость или ограниченность ГЧП, поскольку оно может находить свое выражение во взаимной работе бизнес- ассоциаций и государства по совершенствованию законодательства, проведения мероприятий, в том числе антикоррупционной направленности, так называемое лоббирование.

Урегулированный лоббизм в зарубежной практике рассматривается как одна из мер противодействия коррупции. Здесь мы говорим о признанном, а не теневом лоббизме, который признается как одна из форм коррупции. Лоббизм - это «натуральный канал формирования предложений бизнес структур по преодолению необоснованных административных барьеров, нередко навязываемой системы так называемых «откатов», или полу-

\footnotetext{
1 Астанин В.В. Об эффективных механизмах взаимодействия государство с гражданским обществом в сфере противодействия коррупции // Административное и муниципальное право. 2011. № 4.

2 Проект Федерального закона N 238827-6 «Об основах государственно-частного партнерства в Российской Федерации».

3 См. например, Белицкая А.В. Правовое регулирование государственно-частного партнерства: Монография. - М. : Статут, 2012.
}

чения незаконных преференций, а также протекционизма в отношении избранных компаний, как правило, аффилированных с недобросовестными чиновниками» ${ }^{4}$. Такие предложения формируются в рамках бизнес- сообществ.

Наиболее крупными и влиятельными объединениями представителей бизнеса в настоящее время являются Торгово-промышленная палата Российской Федерации, общероссийские общественные организации «Российский союз промышленников и предпринимателей», «деловая Россия» и «ОПОРА России». В данном случае, позитивным примером ГЧП в сфере противодействия коррупции является совместная работа указанных объединений с Минтруда России. Такая работа предусмотрена пп. «б» п. 25 Указа Президента РФ от 02.04.2013 «0 мерах по реализации отдельных положений Федерального закона «0 противодействии коррупции» ${ }^{5}$ и предусматривает разработку методических рекомендаций по вопросам ст.13.3 «Обязанность организаций принимать меры по предупреждению коррупции» ФЗ «О противодействии коррупции».

Очевидна попытка привлечь институты гражданского общества к решению задач по выработке руководства по предупреждению коррупции в частном секторе, и снова в этой инициативе проглядывается публично-правовой подход: ответственным федеральным органом по данной работе является Минтруда России и социальной защиты, которое в свое время отвечало за реализацию деятельности в сфере борьбы с коррупцией в публичном секторе.

Помимо указанной работы, бизнес-сообществом был проведен ряд антикоррупционных мероприятий:

21 сентября 2012 г. принята и подписана руководителями РСПП, ТПП, Деловой России и «ОПОРы России» Антикоррупционная хартия российского бизнеса ${ }^{6}$ и Дорожная карта по ее реализации ${ }^{7}$, решение о разработке которой было принято президиумом Совета при Президенте РФ по противо-

\footnotetext{
4 Астанин В.В. «О возможностях участия структур гражданского общества в лоббистской деятельности через мониторинг правоприменения» // Мониторинг правоприменения. 2012. № 3. Стр. 4.

СЗ РФ от 08.04.2013, № 14, ст. 1670.

6 http://media.rspp.ru/document/1/3/9/39a4f16cbc9842cb31d 78754a80fd593.pdf

http://media.rspp.ru/document/1/f/1/f1b5426b5ca7164a8f30 7affc68278f6.pdf
} 
действию коррупции от 04.10.2011². В данном документе отражены все основные мировые подходы по предупреждению возникновения коррупционных рисков в организациях. Содержание Хартии не вызывает нареканий, в «Дорожной карт» к ней предусмотрено создание координирующего органа Объединенного комитета, который по сути является представительно-исполнительным и призван определить организационные аспекты ГЧП. Но, к сожалению, в поправках в антикоррупционное законодательство последних двух лет нельзя увидеть воплощение идей, заложенных в Хартии.

в 2013 году РСПП выступил инициатором создания «Белой книги» ${ }^{9}$ "Деловой двадцатки» (В20) лидерам стран «Группы двадцати» (G20). Одной из основных и совместных целей В20 и G20 является глобализация экономики при совершенствовании антикоррупционных мер в частном секторе. Для принятия странами «Группы двадцати» мировым бизнес сообществом предложен на рассмотрение в сентябре 2013 г. ряд мер, направленных на большее взаимодействие между бизнесом и государством по вопросам антикоррупции, увеличение информационной открытости, наращение нетерпимости коррупции в компаниях путем проявления активной позиции представителей организаций в борьбе с коррупцией с наделением их дополнительными полномочиями. Особое место уделено вопросу взаимодействия представителей государства и бизнеса в рамках осуществления закупок, именно государства должны поддерживать и поощрять компании в ведении дел открыто и честно в ходе осуществления торговли за границами своей страны. Также ряд рекомендаций касается развития и внедрения образовательных технологий. Предлагается обучать антикоррупции сотрудников компаний, бенефициаров по вопросам кредитных отношений, а также развития такого образовательного направления в ВУЗах. В20 рекомендует правительствам G20 внедрять в существующие программы повышения квалификации государственных служащих последние наработки компаний по формированию правомерного поведения сотрудников, начиная с 2014 года. Правительства должны приглашать компании В20 и представителей бизнес ассоциаций для развития программ для государственных служащих и обмена опытом по реализации своих комплаенс программ.

\footnotetext{
8 http://pспп.pф/news/view/2065

9 http://b20russia.com/B20_WhiteBook_web.pdf (cтp. 56-59)
}

Исследование «Противодействие корпоративной преступности», проведенное юрфирмой Vegas Lex под эгидой РCПП. Одно из первых масштабных исследований по тематике корпоративного мошенничества, которое свидетельствует о признании представителями бизнеса существующей проблемы (39\% респондентов) и предлагает пути ее разрешения. Основными инструментами противодействия корпоративному мошенничеству могли бы стать кодекс корпоративного поведения, политики противодействия коррупционному мошенничеству и специальные антикоррупционные регламенты основных бизнес процессов, и проч. мероприятия.

Развитие института Уполномоченного по правам предпринимателей в России, предложенное «ОПОРОЙ России».

Можно оценивать как позитивный пример привлечения бизнеса к вопросам противодействия коррупции, через которое опосредованно реализуются лоббистские возможности.

Для закрепления за бизнес-сообществом статуса участника политического процесса необходимо определить, кто будет представлять интересы бизнеса. На наш взгляд, с данной ролью могут успешно справиться (и справляются, исходя из проведенных и запланированных мероприятий) рассмотренные выше крупные организаций от бизнеса ${ }^{10}$.

Оппонентами объединенных усилий бизнеса в рамках взаимоотношений с государством выступают приверженцы GR (Government Relations) менеджмента, суть которого сводится к созданию в крупных компаниях GR - подразделения, занимающегося определением блока вопросов, по которым систематически происходит неизбежное взаимодействие данной компании с государственными органами. Основным инструментом данной управленческой технологии является прямое лоббирование интересов одной конкретной компании $^{11}$. Контраргументами лоббизма группой предпринимателей является разобщенность интересов разных компаний и бюрократизация процесса их интеграции. С данными аргументами можно со-

\footnotetext{
10 Куракин А.В. Вопросы использования зарубежного опыта борьбы с коррупцией в правовом регулировании государственно-служебных отношений // Государство и право. 2003. 一 № 8 .

11 Болгова A.H. GR - менеджмент - инструмент цивилизованного лоббизма // Вестник Пермского университета. 2009. Вып. 1 (5) . Стр. 55.
} 
гласиться, но в отношениях компания-государство в наибольшей степени прослеживается коррупционная составляющая, нежели в объединении представителей. Таким образом, в условиях официального признания лоббизма данные подразделения могут быть субъектами отстаивания интересов без коррупционных практик.

В рамках придания политического статуса бизнес- сообществам возможно развитие такого института как парламентский контроль, который также является одной из мер по профилактике коррупции. Думается, что участие бизнес- сообществ в парламентском контроле обосновывается тем, что данный вид контроля осуществляется не только самим парламентом, но и избирателями, которые этот парламент избрали. Поэтому данный вид контроля называют еще политическим. Как отмечает Т.В. Милушева «парламентский контроль необоснованно трактовать как сугубо государственный. Он представляет собой опосредованную форму общественного контроля, своего рода «мостик» между общественным и государственным контролем» ${ }^{12}$. Парламентский контроль, осуществляемый союзами предпринимателей, может осуществляться через парламентские слушания. Крупные союзы предпринимателей как субъекты лоббирования могут осуществлять эту деятель- ность либо посредствам института Уполномоченного при Президенте Российской Федерации по защите прав предпринимателей ${ }^{13}$.

Данный институт является новым для российской правовой системы, был построен по аналогии действующих омбудсменов по защите прав человека и по правам ребенка ${ }^{14}$. Правовую основу составляет Федеральный закон от 7 мая 2013 г. «Об уполномоченных по защите прав предпринимателей в Российской Федерации» ${ }^{15}$. Одной из задач Уполномоченного является взаимодействие с предпринимательским сообществом.

Необходимо усилить взаимопроникновение частной и публичной сферы противодействия коррупционным преступлениям. Такого взаимопроникновения можно добиться использованием частноправовых институтов в публично-правовой сфере и наоборот. Другим инструментом может являться аутсорсинг ${ }^{16}$. Можно делегировать полномочия в сфере формирования антикоррупционной политик в частных компаниях крупным политизированным бизнес-сообществам. Разработка субъектами, которые будут работать с учетом их пожеланий, не будет восприниматься как навязывание, разработка типичных кодексов или программ, развитие частного сектора, но с контролем за этим процессом со стороны государства.

\section{Библиография:}

1. Костенников М.В., Куракин А.В., Марьян А.В. Административно-правовое регулирование противодействия коррупционным рискам в системе государственной гражданской службы Российской Федерации. - Домодедово, 2011.

2. Астанин В.В. Об эффективных механизмах взаимодействия государства с гражданским обществом в сфере противодействия коррупции. // Административное и муниципальное право. - 2011. - 4. - C. 5-8.

3. Куракин А.В. Международно-правовые источники административного права в сфере противодействия коррупции в системе государственной службы Российской Федерации // Административное и муниципальное право. - 2013. - 3. - C. 240-249. DOI: 10.7256/1999-2807.2013.03.7.

12 Милушева Т.В. Общественный контроль: проблемы формирования т перспективы развития // Вестник Югорского государственного университета. 2008 . Вып. 4 (11). Стр. 56.
13 Куракин А.В. Вопросы использования зарубежного опыта борьбы с коррупцией в правовом регулировании государственно-служебных отношений // Государство и право. 2003. - № 8 .

14 Мохов А.А. Институт Уполномоченного по правам предпринимателей в России // Предпринимательское право. Приложение «Бизнес и право в России и за рубежом». 2012. N 4. Стр. 12.

15 Федеральный закон от 07.05.2013 № 78-Ф3 «Об уполномоченных по защите прав предпринимателей в Российской Федерации» // С3 РФ. — 2013. — № 19. - Ст.2305.

16 Филатова А.В. Аутсорсинг административно-управленческих решений // Предпринимательское право. 2009. № 1. 
4. Куракин А.В., Костенников М.В. Административно-правовое противодействие коррупции в системе государственной службы и в деятельности сотрудников полиции Российской Федерации и зарубежных государств // NB: Российское полицейское право. - 2013. - 1. - C. 65-83. URL: http://www.enotabene.ru/pm/article_735.html

5. Астанин В.В. Противодействие коррупции и возмещение ущерба от нее // NB: Административное право и практика администрирования. - 2013. - 7. - C. 88-99. URL: http://www.e-notabene.ru/al/ article_9924.html

6. Куракин А.В., Лаврентьева О.О. Принципы государственной гражданской службы в механизме противодействия коррупции // Административное и муниципальное право. - 2012. - 9. - С. 15-24.

7. Евстифеев В.В., Куракин А.В., Марьян А.В. Проблемы противодействия коррупции в системе государственной службы // Административное и муниципальное право. - 2010. - 4. - С. 32-36.

\section{References (transliterated):}

1. Koctennikov M.V., Kupakin A.V., Mar'yan A.V. Adminictpativno-ppavovoe pegulipovanie protivodeistviya korruptsionnym riskam $\mathrm{v}$ sisteme gosudarstvennoi grazhdanskoi sluzhby Rossiiskoi Federatsii. Domodedovo, 2011.

2. Astanin V.V. Ob effektivnykh mekhanizmakh vzaimodeistviya gosudarstva s grazhdanskim obshchestvom $\mathrm{v}$ sfere protivodeistviya korruptsii. // Administrativnoe i munitsipal'noe pravo. - 2011. - 4. - C. 5-8.

3. Kurakin A.V.Mezhdunarodno-pravovye istochniki administrativnogo pravav sfere protivodeistviya korruptsiiv sisteme gosudarstvennoi sluzhby Rossiiskoi Federatsii // Administrativnoe i munitsipal'noe pravo. - 2013. 3. - C. 240-249. DOI: 10.7256/1999-2807.2013.03.7.

4. Kurakin A.V., Kostennikov M.V.Administrativno-pravovoe protivodeistviekorruptsiiv sistemegosudarstvennoi sluzhby i v deyatel'nosti sotrudnikov politsii Rossiiskoi Federatsii i zarubezhnykh gosudarstv // NB: Rossiiskoe politseiskoe pravo. - 2013. - 1. - C. 65-83. URL: http://www.e-notabene.ru/pm/article_735. html

5. Astanin V.V. Protivodeistvie korruptsii i vozmeshchenie ushcherba ot nee // NB: Administrativnoe pravo i praktika administrirovaniya. - 2013. - 7. - C. 88-99. URL: http://www.e-notabene.ru/al/article_9924. html

6. Kurakin A.V., Lavrent'eva 0.O. Printsipy gosudarstvennoi grazhdanskoi sluzhby v mekhanizme protivodeistviya korruptsii // Administrativnoe i munitsipal'noe pravo. - 2012. - 9. - C. 15-24.

7. Evstifeev V.V., Kurakin A.V., Mar'yan A.V. Problemy protivodeistviya korruptsii v sisteme gosudarstvennoi sluzhby // Administrativnoe i munitsipal'noe pravo. - 2010. - 4. - C. 32-36. 